EXTENDED REPORT

\title{
EULAR randomised controlled trial of pulse cyclophosphamide and methylprednisolone versus continuous cyclophosphamide and prednisolone followed by azathioprine and prednisolone in lupus nephritis
}

\author{
C-S Yee, C Gordon, C Dostal, P Petera, J Dadoniene, B Griffiths, B Rozman, D A Isenberg, \\ G Sturfelt, O Nived, J H Turney, A Venalis, D Adu, J S Smolen, P Emery
}

Ann Rheum Dis 2003;63:525-529. doi: 10.1136/ard.2002.003574

See end of article for authors' affiliations

Correspondence to:

Dr Caroline Gordon,

Reader and Consultant

Rheumatologist,

Department of

Rheumatology, The

Medical School, University

of Birmingham,

Birmingham B15 2TT, UK;

p.c.gordon@bham.ac.uk

Accepted 4 June 2003

\begin{abstract}
Objective: To compare the efficacy and side effects of intermittent pulse cyclophosphamide plus methylprednisolone with continuous oral cyclophosphamide plus prednisolone, followed by azathioprine, in patients with proliferative glomerulonephritis caused by systemic lupus erythematosus (SLE).

Methods: A multicentre randomised controlled trial was conducted between June 1992 and May 1996 involving eight European centres. All patients satisfied the American College of Rheumatology criteria for SLE and had biopsy proven proliferative lupus nephritis. All received corticosteroids in addition to cytotoxic drugs, as defined in the protocol, for two years. The trial was terminated after four years as recruitment was disappointing.

Results: 32 SLE patients with lupus nephritis were recruited: 16 were randomised to intermittent pulse cyclophosphamide and 16 to continuous cyclophosphamide plus azathioprine. Mean duration of follow up was 3.7 years in the continuous group (range 0 to 5.6) and 3.3 years in the pulse group (range 0.25 to 6). Three patients were excluded from the pulse therapy group as they were later found to have pure mesangial glomerulonephritis. Two patients in the continuous therapy group developed end stage renal failure requiring dialysis, but none in the intermittent pulse therapy $(p=0.488 ; N S)$. There were similar numbers of side effects and withdrawals from treatment in both groups. There were three deaths: two in the intermittent pulse therapy group and one in the continuous therapy group.

Conclusions: There was no statistically significant difference in efficacy and side effects between the two regimens. Infectious complications occurred commonly, so careful monitoring is required during treatment.
\end{abstract}

$\mathrm{T}$ he prognosis of systemic lupus erythematosus (SLE) has improved considerably over the last 40 years. ${ }^{1}$ However, many studies have shown that lupus nephritis is associated with a poorer outcome..$^{2-4}$ Hence much interest has been generated in the use of cytotoxic drugs in the treatment of lupus nephritis, as high dose corticosteroids alone is often inadequate and is associated with unacceptable side effects. There have been relatively few controlled studies on the best treatment for lupus nephritis.

Cyclophosphamide has emerged as the mainstay of treatment to induce remission, following results from NIH studies that showed that intermittent pulse cyclophosphamide treatment was superior to azathioprine and steroids. ${ }^{5-8}$ Unfortunately, there has been a division in opinion among physicians over whether it is best to give cyclophosphamide by intermittent pulse therapy or by continuous therapy.

This trial was designed to compare intermittent pulse cyclophosphamide and methylprednisolone with oral continuous cyclophosphamide and prednisolone for three months, followed by continuous azathioprine and prednisolone. The intermittent pulse cyclophosphamide protocol used in this trial was based on the Birmingham vasculitis protocol, but the drug dose was reduced by $33 \%$ and the interval between pulses increased owing to the frequent occurrence of cytopenias when the original vasculitis protocol was used in SLE patients. ${ }^{9} 10$

\section{METHODS}

\section{Subjects and setting}

An open label multicentre randomised controlled trial was conducted between June 1992 and May 1996 at eight European centres: Prague, Vienna, Vilnius, Leeds, Ljubljana, London, Lund, and Birmingham. Patients were eligible if they were aged 16 to 65 years, satisfied American College of Rheumatology criteria for SLE, ${ }^{11}$ and had biopsy proven proliferative glomerulonephritis caused by SLE. The study was approved by the ethics committees at all participating centres, and signed consent was obtained from all patients before entry into the trial.

Renal biopsy was assessed locally at individual centres using standard WHO classification. ${ }^{12}$ Patients were not eligible if they had had any cyclophosphamide or azathioprine treatment within the preceding three weeks, had pure membranous or pure mesangial proliferative glomerulonephritis on biopsy, previous treatment with cyclophosphamide for more than three months, allergy to the study drugs, previous malignancy, primary immunodeficiency (except complement components), or non-lupus-related renal disease.

The patients were stratified according to the presence of renal failure (defined as creatinine clearance less than $50 \mathrm{ml} /$ min) and subsequently underwent block randomisation to either intermittent pulse therapy or continuous therapy. This trial was aimed to follow patients for five to 10 years; 
however, entry into the trial was terminated after four years as patient recruitment was disappointing and many patients had been withdrawn.

\section{Intermittent pulse therapy protocol}

Intermittent pulse cyclophosphamide therapy was given intravenously at a dose of $10 \mathrm{mg} / \mathrm{kg}$ three weekly for four doses, then orally at the same dose split over two days at four weekly interval for nine months, and finally at six weekly intervals for 12 months (appendix 1). Hence the total duration of treatment was two years. If the nadir neutrophil count at day 7 to 14 after the last pulse was greater than $4000 / \mu \mathrm{l}$, the next dose of cyclophosphamide was increased by $25 \%$. The maximum bolus dose of cyclophosphamide, regardless of weight, was $1000 \mathrm{mg}$. Dosage reductions were advised for cytopenias and renal impairment. If cytopenia (neutrophil count $<2000 / \mu \mathrm{l}$ or platelet count $<100000 / \mu \mathrm{l}$ ) occurred before bolus therapy after the last pulse, the bolus would be delayed until the cell counts were restored. If cytopenia recurred when the next pulse was due, the cyclophosphamide bolus was reduced by $25 \%$ unless there was bone marrow evidence that the cytopenia was caused by the SLE (rather than by previous cytotoxic therapy). In the presence of renal impairment, the cyclophosphamide dose was reduced to 7.5 $\mathrm{mg} / \mathrm{kg}$ if serum creatinine was between 250 and $500 \mu \mathrm{mol} / \mathrm{l}$ (inclusive), and $5 \mathrm{mg} / \mathrm{kg}$ if serum creatinine was more than $500 \mu \mathrm{mol} / \mathrm{l}$.

Pulse methylprednisolone was given intravenously at a dose of $6.6 \mathrm{mg} / \mathrm{kg}$ immediately before each intravenous pulse of cyclophosphamide and then orally at the same dose split over two days before each oral cyclophosphamide pulse (appendix 1). The maximum bolus dose of methylprednisolone, regardless of weight, was $1000 \mathrm{mg}$. No dosage modification was required for cytopenias or renal impairment.

Low dose daily oral prednisolone was given at an initial dose of $0.3 \mathrm{mg} / \mathrm{kg} /$ day to control non-renal lupus symptoms, reducing by $0.1 \mathrm{mg} / \mathrm{kg} /$ day with each pulse if possible to a maintenance dose of $0.05 \mathrm{mg} / \mathrm{kg} /$ day, or $0.1 \mathrm{mg} / \mathrm{kg} / \mathrm{day}$ if necessary. Metoclopramide or ondansetron were recommended as antiemetics, and mesna was given orally as three doses, each at $25 \%$ of the cyclophosphamide dose in milligrams, at 0,4 , and 18 hours after cyclophosphamide, to prevent bladder toxicity.

\section{Continuous therapy protocol}

Daily oral cyclophosphamide was given at a dose of $2 \mathrm{mg} / \mathrm{kg} /$ day for three months. After three months, the oral cyclophosphamide was changed to daily oral azathioprine at a dose of $1.5 \mathrm{mg} / \mathrm{kg} / \mathrm{day}$. In the presence of renal impairment, the dose of cyclophosphamide was reduced to $1.75 \mathrm{mg} / \mathrm{kg} / \mathrm{day}$ if the serum creatinine was between 250 and $500 \mu \mathrm{mol} / \mathrm{l}$ (inclusive) and to $1.5 \mathrm{mg} / \mathrm{kg} /$ day if the serum creatinine was more than $500 \mu \mathrm{mol} / \mathrm{l}$. If a new cytopenia developed, cyclophosphamide or azathioprine was discontinued and a bone marrow biopsy was advised to assess whether this was caused by drugs or lupus. If lupus was responsible, treatment was resumed at the same dose. If therapy was responsible, it was restarted at $25 \%$ lower dose once the cell count was above the lower limits. Following the development of severe neutropenia in several patients on this regimen, the dose of oral cyclophosphamide was reduced to $1.5 \mathrm{mg} / \mathrm{kg} / \mathrm{day}$ in September 1994 .

Patients also received daily oral prednisolone starting at $0.85 \mathrm{mg} / \mathrm{kg} / \mathrm{day}$ and reducing according to the protocol (appendix 2). The maximum daily dose of prednisolone was $60 \mathrm{mg}$.

\section{Additional treatment}

All patients were prescribed an $\mathrm{H}_{2}$ receptor antagonist (ranitidine $150 \mathrm{mg}$ at night or cimetidine $400 \mathrm{mg}$ at night) and amphotericin lozenges ( $10 \mathrm{mg}$ four times a day) as prophylaxis while on daily cyclophosphamide and for two weeks with each pulse of cyclophosphamide. Antihypertensive treatment would be given as necessary to keep diastolic blood pressure below $100 \mathrm{~mm} \mathrm{Hg}$.

If patients did not respond satisfactorily, and had increasing proteinuria or deteriorating renal function, additional immunosuppression could be given at any stage in the form of bolus intravenous methylprednisolone ( $1 \mathrm{~g} /$ day for three days), bolus intravenous cyclophosphamide $(5 \mathrm{mg} / \mathrm{kg} /$ day for three days), or plasma exchange (six exchanges).

\section{Assessments}

All patients were assessed three monthly during the two year treatment period. Intercurrent diseases and treatments were recorded during each visit. Investigations that were undertaken before starting treatment, before each pulse therapy, and monthly during continuous therapy included full blood count, erythrocyte sedimentation rate, C reactive protein, serum creatinine, creatinine clearance, 24 hour urine for protein excretion, urine microscopy, urine culture, antinuclear antibody, anti-dsDNA antibody, C3 and C4. In addition, a full blood count was checked weekly in patients on three weekly pulse therapy and oral cyclophosphamide, and two weekly in those on four to six weekly pulse therapy. Patients on azathioprine had a full blood count checked two weekly for the first two months and four weekly thereafter.

\section{End points}

The primary end points were doubling of serum creatinine and renal failure requiring dialysis. Secondary end points were withdrawal from treatment, complications from treatment (infection, malignancy, haemorrhagic cystitis, amenorrhoea, alopecia, or nausea and vomiting), and death.

\section{Statistical analysis}

Based on the opinions of the investigators, it was estimated that $30 \%$ of patients treated with the oral continuous regimen would double their creatinine in 10 years. This study was designed to have the power of $80 \%$ to detect $20 \%$ difference in this outcome between the two regimens with an $\alpha$ error of 0.05 (two sided); hence it was calculated that 75 patients were required in each treatment arm, taking into account an estimated drop out of $20 \%$.

Analysis was on an intention to treat basis using the $\chi^{2}$ test or Fisher's exact test. A probability ( $p$ ) value of less than 0.05 was considered statistically significant.

\section{RESULTS}

Thirty two patients were recruited, 26 of whom were female. Sixteen patients were randomised to pulse therapy and 16 to continuous therapy. Three patients were excluded from the pulse therapy group as they were mistakenly recruited, being later found to have pure mesangial glomerulonephritis on renal biopsy. The baseline characteristics of each group are shown in table 1 . There was no significant difference in these characteristics between the two treatment groups. Duration of follow up was similar in both groups, with mean follow up of 3.7 years in the continuous group (range 0 to 5.6 years) and 3.3 years in the pulse group (range 0.25 to 6 years). Four patients were lost to follow up: two in the continuous therapy group and two in the pulse therapy group. The reasons were moving home away from the study centre, or the patient's decision not to continue with the study. None of the patients in either group required additional immunosuppressive treatment. 


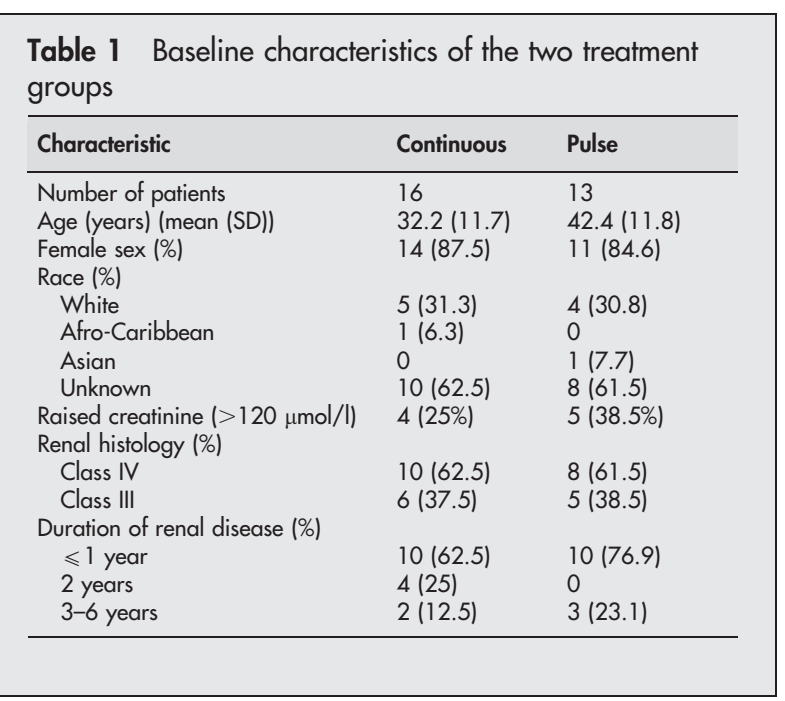

\section{Primary outcomes}

Two patients $(12.5 \%)$ in the continuous therapy group developed end stage renal failure requiring dialysis (table 2 ). One of them doubled the serum creatinine at two years of the treatment protocol and went on to dialysis more than three years after the start of treatment, while the other patient had required dialysis since the start of the study. In the pulse therapy group none of the patients doubled their creatinine or required dialysis. However, this difference was not statistically significant (Fisher's exact test, $\mathrm{p}=0.488$ ).

\section{Secondary outcomes}

There was no significant difference in withdrawal from therapy between the two treatment groups (table 2). There were more neutropenias in the continuous therapy group, and these were also more severe than in the pulse therapy group, but not all were associated with infections. There were similar numbers of infectious complications in both groups: in the continuous therapy group, two were viral, one viral plus bacterial, and one possibly fungal; in the pulse therapy group the infections were predominantly bacterial. There was more nausea and vomiting in the pulse therapy group, but this was predominantly in the oral part of the pulse regimen. There was one case of haemorrhagic cystitis in the continuous group but none in the pulse group. The only malignancy occurring in the study was a bronchial carcinoma in a 62 year old women in the pulse group who had been withdrawn three months into the study because of recurrent bronchopneumonia, possibly related to the tumour.

\begin{tabular}{|c|c|c|}
\hline Outcomes & $\begin{array}{l}\text { Continuous } \\
\text { therapy (\%) }\end{array}$ & $\begin{array}{l}\text { Pulse therapy } \\
\text { (\%) }\end{array}$ \\
\hline Doubled serum creatinine & $1(6.3)$ & 0 \\
\hline Dialysis & $2(12.5)$ & 0 \\
\hline Neutropenia & $3(18.8)$ & $1(7.7)$ \\
\hline Infections & $4(25)$ & $5(38.5)$ \\
\hline Nausea/vomiting & $1(6.3)$ & $3(23.1)$ \\
\hline Haemorrhagic cystitis & $1(6.3)$ & 0 \\
\hline Malignancy & 0 & $1(7.7)$ \\
\hline Permanent amenorrhoea & $1(6.3)$ & $1(7.7)$ \\
\hline Withdrawn from therapy & $7(43.8)$ & $7(53.8)$ \\
\hline Death & $1(6.3)$ & $2(15.4)$ \\
\hline
\end{tabular}

Amenorrhoea occurred in one patient in each group and both of these patients were aged 40 years.

There were three deaths in the study-one in the continuous group with the other two in the pulse group. The only death in the continuous group occurred in a patient who had been withdrawn before starting the study drugs because of rapidly deteriorating renal function and infection. The cause of death in one patient in the pulse group was malignancy, while the other died late ( 3.3 years after the start of treatment) and the cause was not determined.

There was a similar number of withdrawals from treatment in both treatment groups (table 3 ), the majority because of adverse effects. In the pulse therapy group, infections were the main reason for withdrawal, while in the continuous group, neutropenia and infections were the most common reasons for withdrawal. Only one patient in each group had to be withdrawn because of failure to respond to the treatment protocol.

\section{DISCUSSION}

There has been a lack of studies directly comparing treatment with continuous oral cyclophosphamide and intermittent pulse cyclophosphamide. In the NIH study comparing different immunosuppressive regimens (including continuous oral cyclophosphamide and pulse cyclophosphamide), the results were obtained by comparing a few different regimens prescribed over different time periods. ${ }^{5}$ Hence that study has to be interpreted with caution as it was not a properly controlled trial and the comparisons between different regimens were not direct.

Our present study was designed to address this issue. The pulse cyclophosphamide protocol used in this study was modified from the Birmingham vasculitis protocol, with shorter interval between pulses than in the NIH protocol. The rational for this was the rapid induction of disease remission, thereby reducing irreversible damage caused by the disease.

In our study, there was no statistically significant difference between intermittent pulse therapy and continuous therapy with regard to efficacy. Unfortunately, the study had inadequate power to detect a difference in efficacy between the two treatment regimens because recruitment proved harder than expected. Many physicians became reluctant to enter patients because of concerns that the oral regimen was slower to work and more toxic than the pulse regimen, following development of severe neutropenia in the continuous group. This led to the premature termination of the study.

There was a trend towards less severe adverse effects in the intermittent pulse regimen compared with the continuous oral regimen. Infections were common and occurred in about $30 \%$ of patients in both groups; hence there is a need for careful monitoring in all patients on cyclophosphamide treatment. There have been no cases of haemorrhagic cystitis in the pulse cyclophosphamide regimen, which is consistent with previous studies involving pulsed cyclophosphamide..$^{5-8}$ This is reassuring, as potential bladder toxicity on oral

\begin{tabular}{lll|}
\hline $\begin{array}{l}\text { Table } 3 \text { Reasons for withdrawal from } \\
\text { treatment }\end{array}$ \\
\begin{tabular}{lll} 
Reason for withdrawal & $\begin{array}{l}\text { Continuous } \\
\text { therapy }\end{array}$ & Pulse therapy \\
\hline $\begin{array}{l}\text { Adverse effects } \\
\text { Failure to respond to } \\
\text { treatment }\end{array}$ & $6(37.5)$ & $5(38.5)$ \\
Patient's choice & $1(6.3)$ & $1(7.7)$ \\
& 0 & $1(7.7)$ \\
\hline
\end{tabular} \\
\hline
\end{tabular}


cyclophosphamide is a major reason for physicians preferring pulsed cyclophosphamide to continuous cyclophosphamide.

The results of our study are similar to those of another study done in Hong Kong, which compared intermittent intravenous pulse cyclophosphamide with sequential oral cyclophosphamide followed by azathioprine. ${ }^{13}$ However, it was not a randomised controlled trial, as the outcomes of one centre using pulse cyclophosphamide were compared with outcomes from another centre using sequential oral treatment. The dose of pulse cyclophosphamide used in that study was smaller, with longer intervals between pulses, than in the present study.

Although our study showed similar efficacy between the pulse and continuous regimens, one has to bear in mind that the duration of continuous oral cyclophosphamide was three months, which is much shorter than in previous studies with continuous cyclophosphamide. Longer courses of continuous cyclophosphamide may result in better efficacy, but this would be at the expense of more adverse effects-particularly haemorrhagic cystitis, which occurred in up to $17 \%$ of patients in previous studies. ${ }^{5}$ In the NIH study comparing pulse intravenous cyclophosphamide and oral cyclophosphamide, a difference in renal outcome favouring pulse therapy only became apparent after five years. ${ }^{5}$ Hence, the duration of follow up in out present trial may not be sufficient to show a difference between these two treatments.

In conclusion, this study shows that there is no great difference in efficacy between the oral continuous and intermittent pulse regimes for cyclophosphamide, but the initial dose of $2 \mathrm{mg} / \mathrm{kg}$ oral cyclophosphamide was felt by the investigators to be too toxic to persist with. The intermittent intravenous pulse regimen appears to be better tolerated than oral continuous treatment, with less severe adverse effects. We believe this effect would be more apparent if the oral pulse was replaced by intravenous pulse, as many patients in the pulse therapy group develop severe nausea and vomiting during the oral part of this regimen. It is therefore not surprising that the intermittent intravenous pulse regimen has been widely adopted as the mode of choice for cyclophosphamide administration in the treatment of lupus nephritis. ${ }^{14}{ }^{15}$

Further studies with pulse cyclophosphamide are still required to define its role in the treatment of proliferative lupus nephritis. The efficacy and safety of shorter courses of pulse cyclophosphamide followed by other immunosuppressive agents such as azathioprine, cyclosporin A, and mycophenolate mofetil, need to be evaluated in clinical trials.

\section{ACKNOWLEDGEMENTS}

This study was supported by the EULAR Standing Committee on International Clinical Studies including Therapeutic Trials (ESCIST), Lupus UK, and the Swedish Medical Research Council (grant 13489).

\section{Authors' affiliations}

C-S Yee, C Gordon, Rheumatology, University of Birmingham, UK C Dostal, Institute of Rheumatology, Prague, Czech Republic

P Petera, J S Smolen, Rheumatic Diseases Centre Lainz Hospital and Ludwig Bolzmann Institute for Rheumatology and Balneology, Austria J Dadoniene, A Venalis, Internal Medicine and Rheumatology Vilnius University, Lithuania

B Griffiths, Department of Rheumatology, University of Leeds, United Kingdom

B Rozman, University Medical Centre, Liubliana, Slovenia

D A Isenberg, Rheumatology, University College London, UK

G Sturfelt, Department of Rheumatology, Lund University Hospital, Sweden

O Nived, Rheumatology, Lund University Hospital, Sweden

J H Turney, Renal Unit, Leeds General Infirmary, UK
D Adu, Renal Medicine, University Hospitals Birmingham NHS Trust, UK P Emery, Rheumatology, University of Leeds, United Kingdom

\section{APPENDIX 1}

\section{Intermittent pulse therapy protocol}

\begin{tabular}{|c|c|c|c|}
\hline $\begin{array}{l}\text { Time } \\
\text { (week) }\end{array}$ & Route & Cyclophosphamide dose & Prednisolone dose \\
\hline 0 & iv & $10 \mathrm{mg} / \mathrm{kg} \times 1$ & $6.6 \mathrm{mg} / \mathrm{kg} \times 1$ \\
\hline 3 & iv & $10 \mathrm{mg} / \mathrm{kg} \times 1$ & $6.6 \mathrm{mg} / \mathrm{kg} \times 1$ \\
\hline 6 & iv & $10 \mathrm{mg} / \mathrm{kg} \times 1$ & $6.6 \mathrm{mg} / \mathrm{kg} \times 1$ \\
\hline 9 & iv & $10 \mathrm{mg} / \mathrm{kg} \times 1$ & $6.6 \mathrm{mg} / \mathrm{kg} \times 1$ \\
\hline 12 & oral & $5 \mathrm{mg} / \mathrm{kg} \times 2$ & $3.3 \mathrm{mg} / \mathrm{kg} \times 2$ \\
\hline 16 & oral & $5 \mathrm{mg} / \mathrm{kg} \times 2$ & $3.3 \mathrm{mg} / \mathrm{kg} \times 2$ \\
\hline 20 & oral & $5 \mathrm{mg} / \mathrm{kg} \times 2$ & $3.3 \mathrm{mg} / \mathrm{kg} \times 2$ \\
\hline 24 & oral & $5 \mathrm{mg} / \mathrm{kg} \times 2$ & $3.3 \mathrm{mg} / \mathrm{kg} \times 2$ \\
\hline 28 & oral & $5 \mathrm{mg} / \mathrm{kg} \times 2$ & $3.3 \mathrm{mg} / \mathrm{kg} \times 2$ \\
\hline 32 & oral & $5 \mathrm{mg} / \mathrm{kg} \times 2$ & $3.3 \mathrm{mg} / \mathrm{kg} \times 2$ \\
\hline 36 & oral & $5 \mathrm{mg} / \mathrm{kg} \times 2$ & $3.3 \mathrm{mg} / \mathrm{kg} \times 2$ \\
\hline 40 & oral & $5 \mathrm{mg} / \mathrm{kg} \times 2$ & $3.3 \mathrm{mg} / \mathrm{kg} \times 2$ \\
\hline 44 & oral & $5 \mathrm{mg} / \mathrm{kg} \times 2$ & $3.3 \mathrm{mg} / \mathrm{kg} \times 2$ \\
\hline 48 & oral & $5 \mathrm{mg} / \mathrm{kg} \times 2$ & $3.3 \mathrm{mg} / \mathrm{kg} \times 2$ \\
\hline 52 & oral & $5 \mathrm{mg} / \mathrm{kg} \times 2$ & $3.3 \mathrm{mg} / \mathrm{kg} \times 2$ \\
\hline 58 & oral & $5 \mathrm{mg} / \mathrm{kg} \times 2$ & $3.3 \mathrm{mg} / \mathrm{kg} \times 2$ \\
\hline 64 & oral & $5 \mathrm{mg} / \mathrm{kg} \times 2$ & $3.3 \mathrm{mg} / \mathrm{kg} \times 2$ \\
\hline 70 & oral & $5 \mathrm{mg} / \mathrm{kg} \times 2$ & $3.3 \mathrm{mg} / \mathrm{kg} \times 2$ \\
\hline 76 & oral & $5 \mathrm{mg} / \mathrm{kg} \times 2$ & $3.3 \mathrm{mg} / \mathrm{kg} \times 2$ \\
\hline 82 & oral & $5 \mathrm{mg} / \mathrm{kg} \times 2$ & $3.3 \mathrm{mg} / \mathrm{kg} \times 2$ \\
\hline 88 & oral & $5 \mathrm{mg} / \mathrm{kg} \times 2$ & $3.3 \mathrm{mg} / \mathrm{kg} \times 2$ \\
\hline 94 & oral & $5 \mathrm{mg} / \mathrm{kg} \times 2$ & $3.3 \mathrm{mg} / \mathrm{kg} \times 2$ \\
\hline 100 & oral & $5 \mathrm{mg} / \mathrm{kg} \times 2$ & $3.3 \mathrm{mg} / \mathrm{kg} \times 2$ \\
\hline 104 & oral & $5 \mathrm{mg} / \mathrm{kg} \times 2$ & $3.3 \mathrm{mg} / \mathrm{kg} \times 2$ \\
\hline
\end{tabular}

\section{APPENDIX 2}

Prednisolone dose in continuous therapy

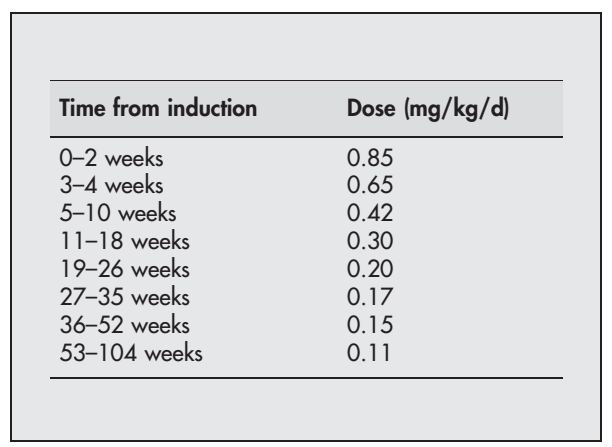

\section{REFERENCES}

1 Uramoto KM, Michet CJ, Thumboo J, Sunku J, O'Fallon WM, Gabriel SE. Trends in the incidence of systemic lupus erythematosus, 1950-1992. Arthritis Rheum 1999;42:46-50.

2 Pistiner M, Wallace DJ, Nessim S, Metzger AL, Klineberg JR. Lupus erythematosus in the 1980s: a survey of 570 patients. Semin Arthritis Rheum 1991;21:55-64.

3 Lee $\mathbf{P}$, Urowitz MB, Bookman AAM, Koehler BE, Smythe HA, Gordon DA, et al. Systemic lupus erythematosus: a review of 110 cases with respect to nephritis, the nervous system, infection, aseptic necrosis and prognosis. Q J Med 1977;46:1-32.

4 Wallace DJ, Podell T, Weiner J, Klineberg JR, Forouzesh S, Dubois EL. Systemic lupus erythematosus-survival patterns: experience with 609 patients. JAMA 1981:245:934-8. 
5 Austin HA, Klippel JR, Balow JE, Le Riche NGH, Steinberg AD, Plotz PH, et al. Therapy of lupus nephritis: controlled trial of prednisone and cytotoxic drugs. N Engl J Med 1986;314:614-19.

6 Boumpas DT, Austin HA, Vaughn EM, Klippel JH, Steinberg AD Yarboro $\mathrm{CH}$, et al. Controlled trial of pulse methylprednisolone versus two regimens of pulse cyclophosphamide in severe lupus nephritis. Lancet 1992;340:741-5.

7 Gourley MF, Austin HA, Scott D, Yarboro CH, Vaughan EM, Muir J, et al. Methylprednisolone and cyclophosphamide, alone or in combination, in patients with lupus nephritis: a randomized controlled trial. Ann Intern Med 1996; 125:549-57.

8 Illei GG, Austin HA, Crane M, Collins L, Gourley MF, Yarboro $\mathrm{CH}$, et al. Combination therapy with pulse cyclophosphamide plus pulse methylprednisolone improves long-term renal outcome without adding toxicity in patients with lupus nephritis. Ann Intern Med 2001;135:248-57.

9 Scott DG, Bacon PA. Intravenous cyclophosphamide plus methylprednisolone in treatment of systemic rheumatoid vasculitis. Am J Med 1984;76:377-84
10 Adu D, Pall A, Luqmani RA, Richards NT, Howie AJ, Emery P, et al. Controlled trial of pulse versus continuous prednisolone and cyclophosphamide in the treatment of systemic vasculitis. QJM 1997;90:401-9.

11 Tan EM, Cohen AS, Fries JF, Masi AT, McShane DJ, Rothfield NF, et al. The 1982 revised criteria for the classification of systemic lupus erythematosus. Arthritis Rheum 1982;25:1271-7.

12 Golbus J, McCune WJ. Lupus nephritis. Classification, prognosis, immunopathogenesis and treatment. Rheum Dis Clin North Am 1994;20:213-42.

13 Mok CC, Ho CTK, Siu YP, Chan KW, Kwan TH, Lau CS, et al. Treatment of diffuse proliferative lupus glomerulonephritis: a comparison of two cyclophosphamide-containing regimens. Am J Kid Dis 2001;38:256-64.

14 Cross J, Jayne D. UK survey on the management of patients with severe lupus nephritis. Abstract 56 of the Renal Association Autumn Meeting 20-21 September 2001. (available online only at http://www.renal.org)

15 Takada K, Illei GG, Boumpas DT. Cyclophosphamide for the treatment of systemic lupus erythematosus. Lupus 2001;10:154-61. 